\title{
Comparison of 3D and 2D acquisition of late gadolinium enhancement in patients with acute, subacute and chronic myocardial infarction
}

\author{
Robert Goetti ${ }^{1 *}$, Sebastian Kozerke ${ }^{2}$, Olivio F Donati ${ }^{1}$, Paul Stolzmann ${ }^{1}$, Roberto Corti ${ }^{1}$, Robert Manka ${ }^{1}$ \\ From 2011 SCMR/Euro CMR Joint Scientific Sessions \\ Nice, France. 3-6 February 2011
}

\section{Purpose}

To assess a late gadolinium enhancement (LGE) imaging single breath-hold 3D inversion recovery sequence for the quantification of myocardial scar mass and transmurality in comparison to a clinically established $2 \mathrm{D}$ acquisition sequence.

\section{Methods}

Ninety patients (84 men, age $54.4 \pm 10.8 \mathrm{y}$, BMI $27.8 \pm 4.5$ $\left.\mathrm{kg} / \mathrm{m}^{2}\right)$ with acute $(\mathrm{n}=30)$, subacute $(\mathrm{n}=30)$ and chronic $(n=30)$ myocardial infarction were included in the study. All imaging was performed on a 1.5-T clinical MR system (Achieva, Philips Medical Systems, Best, the Netherlands). Spatial resolution was identical for 3D and 2D images $\left(1.5 \times 1.5 \mathrm{~mm}^{2}\right.$, slice thickness $8 \mathrm{~mm}$, no slice gap). Image quality was graded on a five-point scale (1: excellent, 5: non-diagnostic). Quantitative analyses of myocardial mass (g), scar mass (g) and scar transmurality (five-point scale: 0: $0 \% ; 1:<25 \% ; 2:<50 \%$; 3: $<75 \% ; 4: 75 \%-100 \%)$ were performed. Intra- and interobserver agreement were assessed for 15 randomly chosen patients (5 of each group).

\section{Results}

Mean image quality was not significantly different in 3D $(1.50 \pm 0.675)$ and $2 \mathrm{D}(1.41 \pm 0.669 ; \mathrm{p}=0.26)$ datasets. Non-diagnostic image quality (score: 5 ) did not occur. Acquisition time was significantly shorter for 3D datasets (26.7 \pm 4.4 sec vs. $367.7 \pm 56.4$ sec; $p<0.001)$. There were no significant differences between $2 \mathrm{D}$ and $3 \mathrm{D}$ datasets in mean myocardial mass (2D: $148.3 \pm 35.1$ g; 3D: $148.1 \pm$ $34.6 \mathrm{~g} ; \mathrm{p}=0.76)$ and scar tissue mass (2D: $31.8 \pm 14.6 \mathrm{~g}$;

\footnotetext{
${ }^{1}$ University Hospital Zurich, Zurich, Switzerland

Full list of author information is available at the end of the article
}
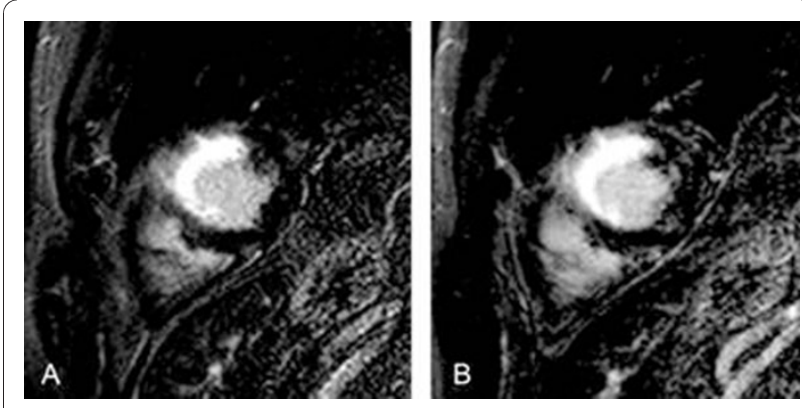

Figure 1 Images of 2D (A) and 3D (B) acquisitions in a 48 y/o male with acute myocardial infarction showing equal image quality and delayed enhancement extent.

3D: $31.6 \pm 15.5 \mathrm{~g} ; \mathrm{p}=0.39$ ) with strong and significant correlation between $2 \mathrm{D}$ and $3 \mathrm{D}$ datasets regarding both myocardial mass $(\mathrm{r}=0.982 ; \mathrm{p}<0.001)$ and scar tissue mass $(r=0.980 ; p<0.001)$. Bland-Altman analysis showed a mean difference of $0.21 \pm 6.64 \mathrm{~g}$ (range: $-19.64-18.44$ g) for myocardial mass and a mean difference of 0.26 $\pm 2.88 \mathrm{~g}$ (range: $-7.15-7.74 \mathrm{~g}$ ) for scar mass between 2D and 3D datasets. Agreement between the two acquisition techniques regarding scar transmurality was excellent for the detection of non-viable segments $(>50 \%$ scar tissue transmurality; $\kappa=0.81)$ and was good $(\kappa=0.75)$ for the more detailed assessment using the five-point transmurality score. Inter- and intra-observer agreements were good to excellent $(\kappa=0.70-0.90)$.

\section{Conclusions}

3D LGE imaging enables accurate quantitative evaluation of scar tissue mass and transmurality with significantly shorter acquisition time compared to $2 \mathrm{D}$ LGE imaging. 


\section{Author details}

${ }^{1}$ University Hospital Zurich, Zurich, Switzerland. ${ }^{2}$ ETH Zurich, Zurich,

Switzerland.

Published: 2 February 2011

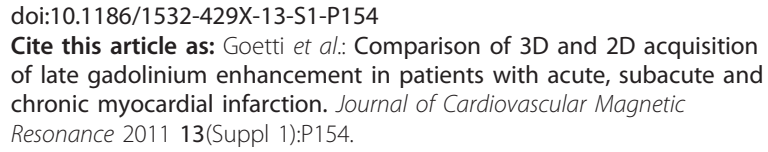

Submit your next manuscript to BioMed Central and take full advantage of:

- Convenient online submission

- Thorough peer review

- No space constraints or color figure charges

- Immediate publication on acceptance

- Inclusion in PubMed, CAS, Scopus and Google Scholar

- Research which is freely available for redistribution 